\title{
The Use of Ground Penetrating Radar in Municipal Solid Waste Landfill Geotechnical Investigation
}

\author{
José Tavares Araruna Júnior ${ }^{1}$, Patrício José Moreira Pires ${ }^{2}$, Débora Lopes Pilotto Domingues ${ }^{1}$ and Tácio Mauro \\ Pereira de Campos ${ }^{1}$ \\ 1. Department of Civil Engineering, Pontifical Catholic University of Rio de Janeiro, Rio de Janeiro RJ 22451-900, Brazil \\ 2. Department of Civil Engineering, Federal University of Espirito Santo, Vitória ES 29075-910, Brazil
}

\begin{abstract}
The use of GPR (ground penetrating radar) as an auxiliary tool in geotechnical and environmental site investigations has increased in Brazil during the past few years. GPR has been used to delineate contamination plumes, to aid in geological modelling, to detect buried structures and in archaeological surveys. This paper describes and discusses the results of a GPR site investigation carried out at Gramacho Municipal Solid Waste Landfill in the State of Rio de Janeiro, Brazil. A field study was conducted to detect failure surfaces in its slopes and within the waste mass. The results have shown that: (1) Slip surfaces could be indicated by small continuous voids within the waste mass since there is a good contrast between the dielectric constant of air and municipal waste; (2) Greenhouse gases pools could also be indicated by large voids within the waste mass since there is a good contrast between the dielectric constant of carbon dioxide, methane and municipal waste; (3) Leachate pools present a high electric conductivity that could be easily detected by GPR.
\end{abstract}

Key words: GPR, landfill, geotechnical investigation, slip surface, leachate, greenhouse gas.

\section{Introduction}

The use of GPR (ground penetrating radar) as an auxiliary tool in geotechnical and environmental site investigation has become more common in Brazil in recent years. GPR has been used to:

- map contaminated areas [1-3];

- aid in geological modelling [4];

- detect buried structures [5-8];

- archaeological survey [9].

However, its use has been subjected to some criticism by the Brazilian technical community and, in some occasion, its usefulness has been put on proof. According to Iyomasa [10], the indiscriminate GPR use with no technical criteria leads to problems in acquisition of the electromagnetic waves and in interpretation of its results.

Araruna Jr. [11] suggested that the most important step in GPR survey planning is the correct definition of

Corresponding author: José Tavares Araruna Júnior, Ph.D., research fields: site investigation and environmental geotechnics. the problem. In order to solve that, some questions need to be addressed, including:

- What are the depth and geometry of the target?

- Is there enough contrasts between the electrical properties of the materials to be surveyed?

- Is there any noise source in the area (e.g., radio antennas, power lines)?

- Is there any data from previous investigations?

Some authors, authors like Porsani [12], and Annan and Cosway [13], have addressed these topics in the past and provided some clues to overcome such difficulties. Even when all the standard procedures are taken into account on the GPR survey planning, the success of the site investigation is not granted. In some cases, the media to be investigated is heterogeneous or it had been extensively modified by human action.

This is the case in municipal solid waste disposal facilities in Brazil, where the waste mass is composed of materials of different sizes, shapes and composition and inappropriate compaction is generally carried out. In this context, despite the use of GPR method in 
landfill surveys seems to be very useful, due to low cost and speed of execution, one must bear in mind the aforementioned difficulties.

This paper describes and discusses the results of a geophysical site investigation employing carried out at Gramacho Municipal Solid Waste Landfill in the State of Rio de Janeiro, Brazil. A GPR field study was conducted to detect failure surfaces in its slopes and within the waste mass. In addition, the GPR profiles were also assessed in order to search leachate and greenhouse gases pools within the landfill.

\section{Gramacho Municipal Solid Waste Landfill}

Gramacho Municipal Solid Waste Landfill is located in the greater Rio de Janeiro area, in the City of Duque de Caxias. It occupies an area of 180 ha and receives circa 9,000 t of waste on a daily basis. As shown in Fig. 1, its location is far from ideal. It is in closing range from two main rivers that cross the metropolitan area (e.g. Iguaçu and Sarapuí), Guanabara Bay and less than $5 \mathrm{~km}$ from the international airport.

Its site is also unfit from the geotechnical point of view. The landfill lies over a $18-\mathrm{m}$ thick soft clay layer, composed not only by 1:1 clay minerals but also from expansive minerals (e.g., smectites).

As a result of small failures on the waste mass and soil foundation a comprehensively monitoring program has been carried out since the late $90 \mathrm{~s}$. Inclinometers were installed at the perimeter of the landfill (Fig. 2), benchmarks were installed on the waste mass and at the perimeter of the landfill, and piezometers were installed within the waste mass.

\section{Materials and Methods}

GPR survey at Gramacho was performed using a ground penetrating radar manufactured by MALA Geoscience, model RAMAC. The equipment, which can be seen in Fig. 3, consists of an acquisition and control unit where the emitted and received electromagnetic waves signals are transferred to a digital monitor (Fig. 4). The monitor not only allows the visualization of the radargrams but also enables them to be stored in a digital media.

Positioning of GPR survey was accomplished by a GPS (global positioning system) unit that allows, through the use of GPS Mapper ${ }^{\mathbb{R}}$ software, plotting it on a Google Earth image.

Survey radargrams were acquires by using 50 - and 100-MHz RTAs (rough terrain antennas). The central frequency of each antenna was chosen in order to provide the travel of the electromagnetic waves up to the desired depth.

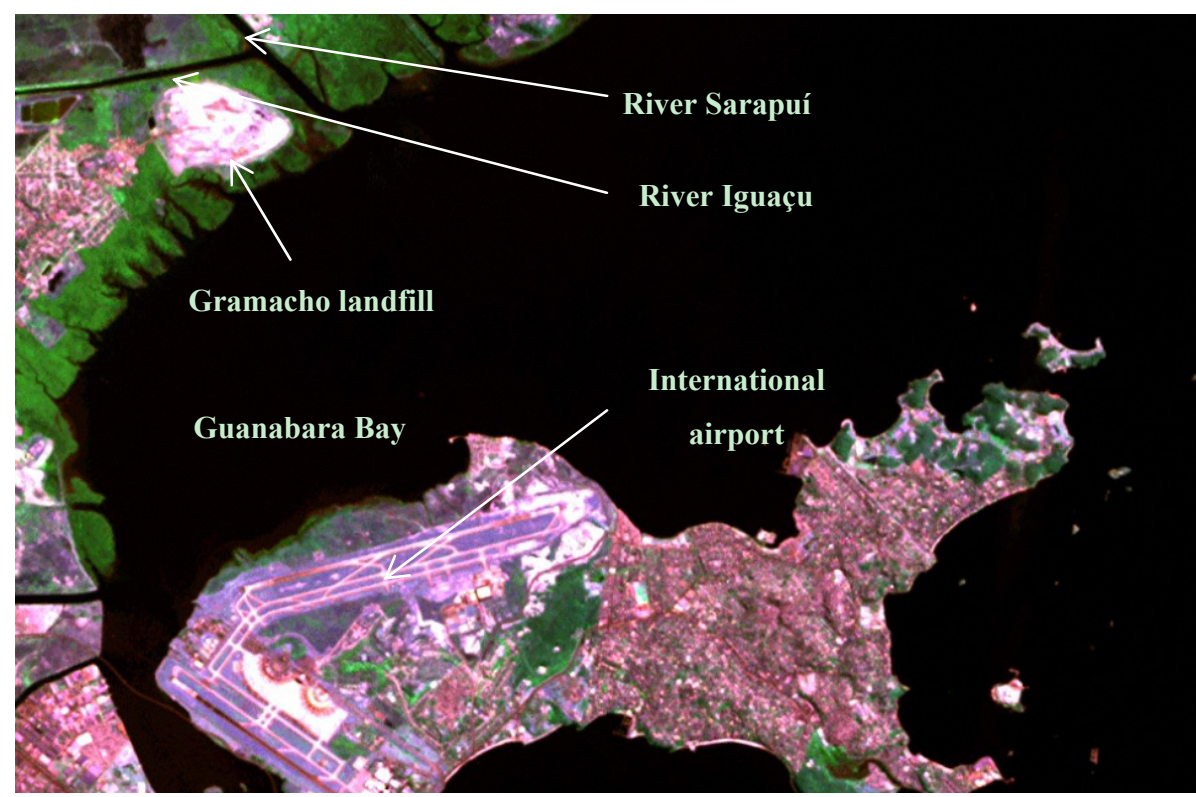

Fig. 1 Gramacho landfill. 


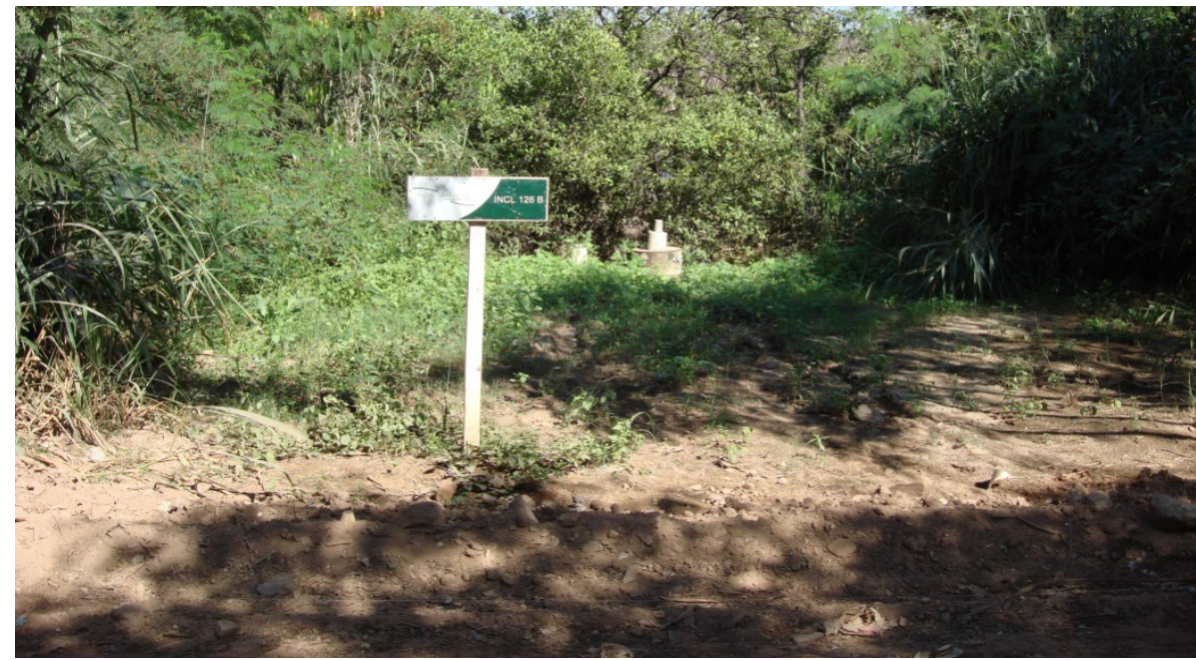

Fig. 2 Inclinometer and benchmark at the perimeter of the landfill.

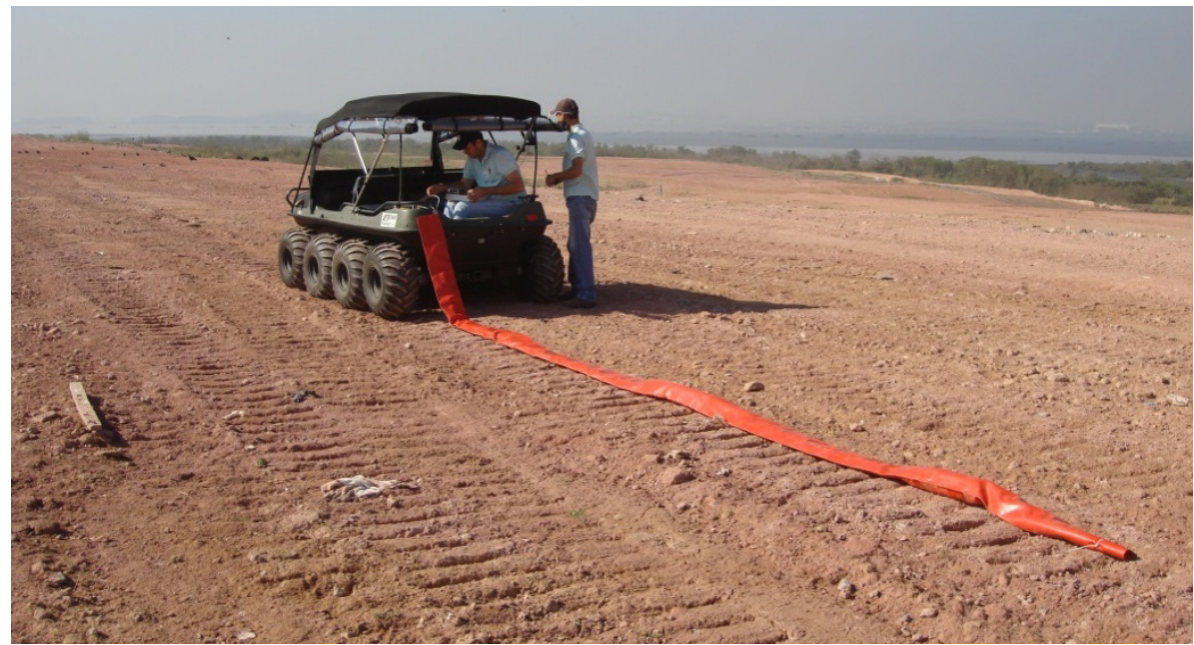

Fig. 3 MALA Geoscience GPR.

Data acquisition was accomplished through the use of GroundVision ${ }^{\circledR}$ software. For most of the GPR profiles the following parameters were used:

- numbers of samples per scan-1,000;

- number of stacks-4;

- range-200 ns;

- scan interval-0.02 m;

- no gain;

- no filter.

The radargrams were processed through the use of RadExplorer ${ }^{\circledR}$ software.

\section{Results and Discussion}

The red line in Fig. 5 shows one location where good contrasts were found during the GPR site investigation.
The legend presented in Fig. 5 represents, in meters, the difference in altitude during the survey.

The radargram of this survey, shown in Fig. 6, presents some interesting features. In fact, after processing, one could see a continuous line delineated by the blue line in Fig. 7, that might well represent a slip surface.

After processing, it is feasible to delineate the possible slip surface. As Fig. 7 shows, the blue line indicates its position within the waste mass. This hypothesis was suggested based upon the fact that: (1) The slip surface presents a different texture from the texture of the waste mass; (2) The radargram evidenced a differential flow path through the surface delineated by the blue line. 


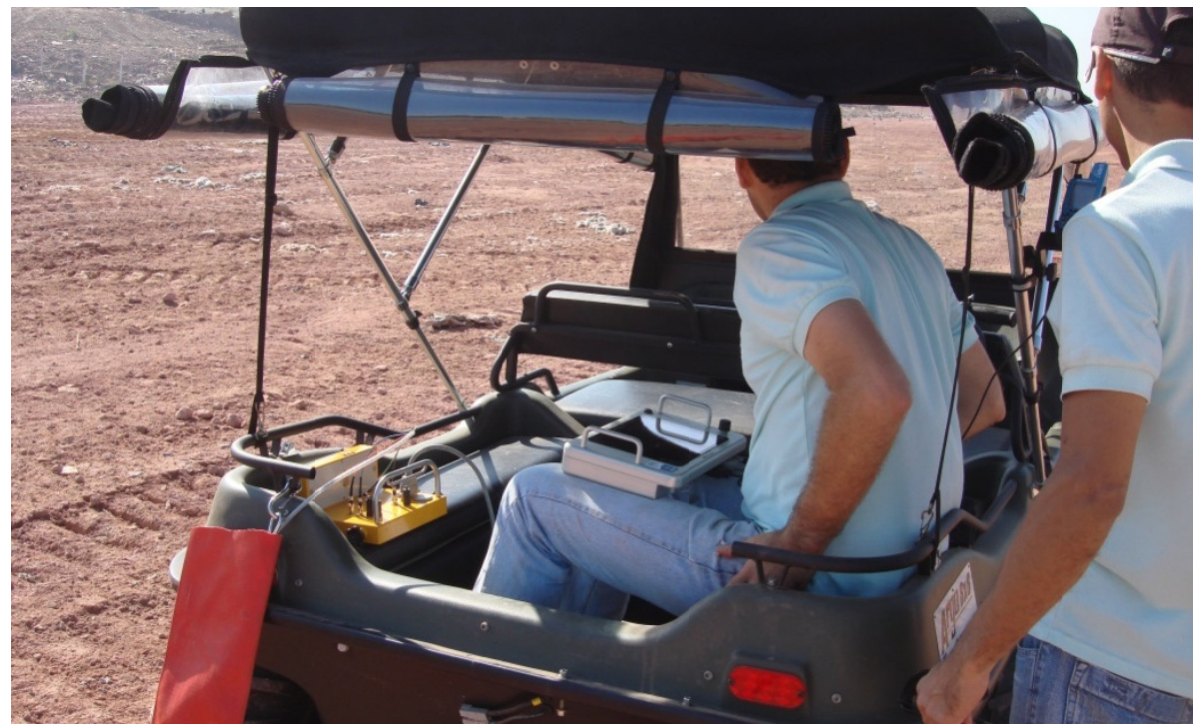

Fig. 4 GPR monitor and GPS unit.

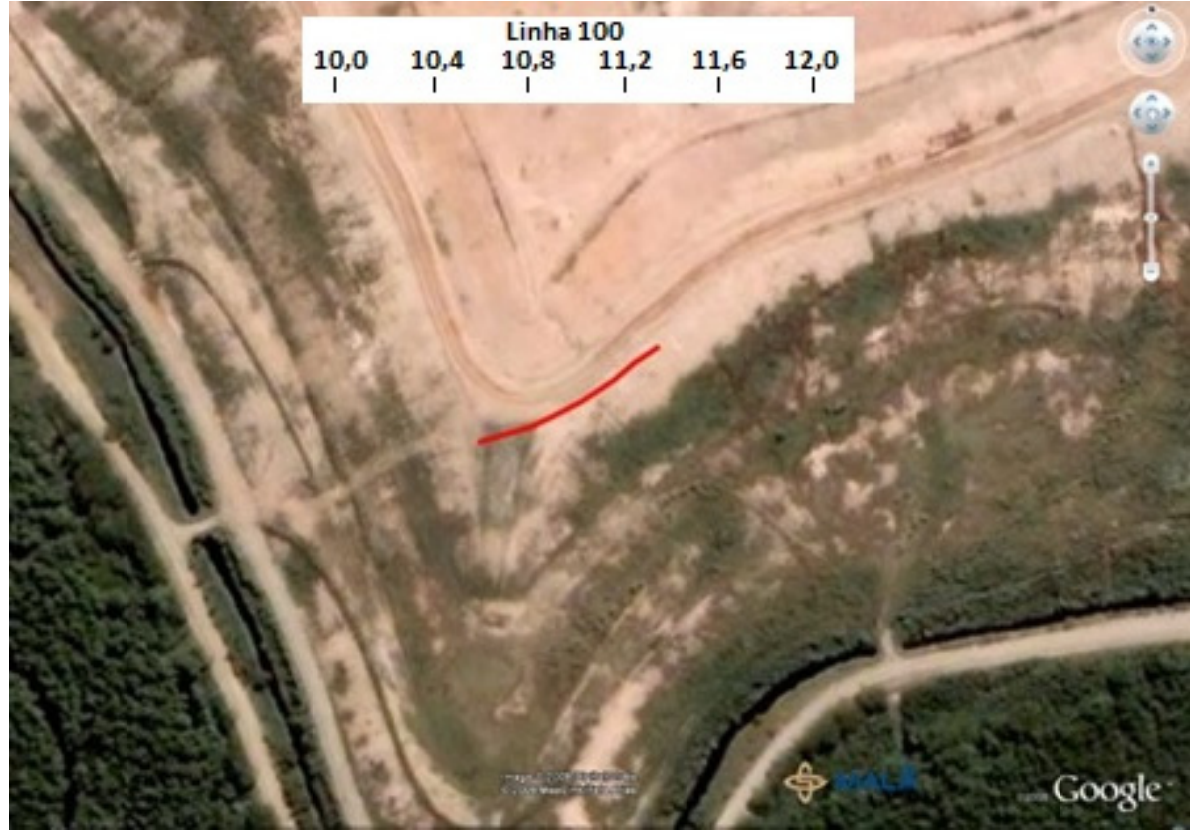

Fig. 5 GPR survey location.

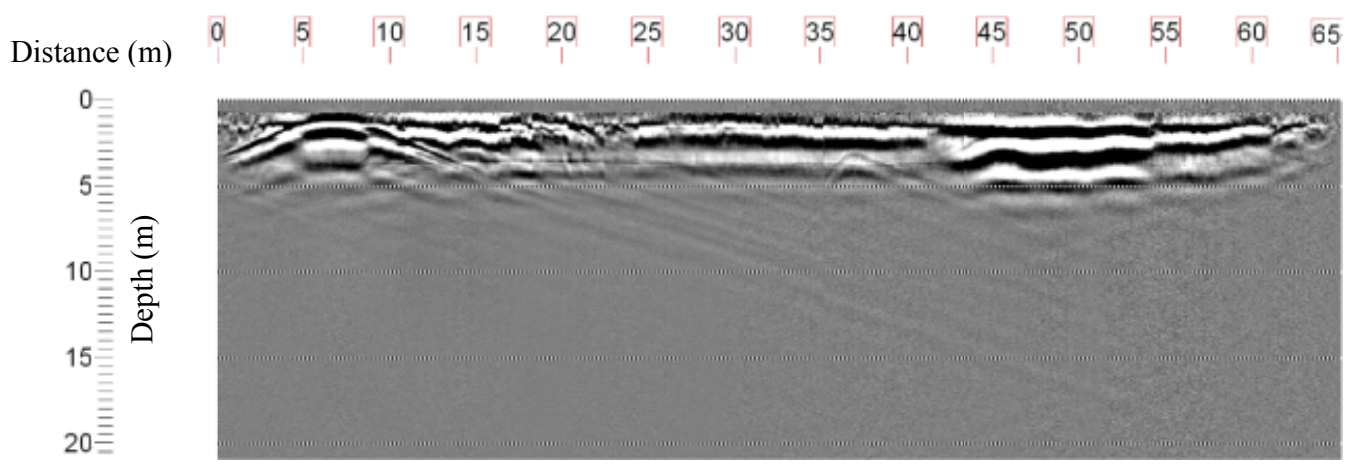

Fig. 6 GPR radargram. 


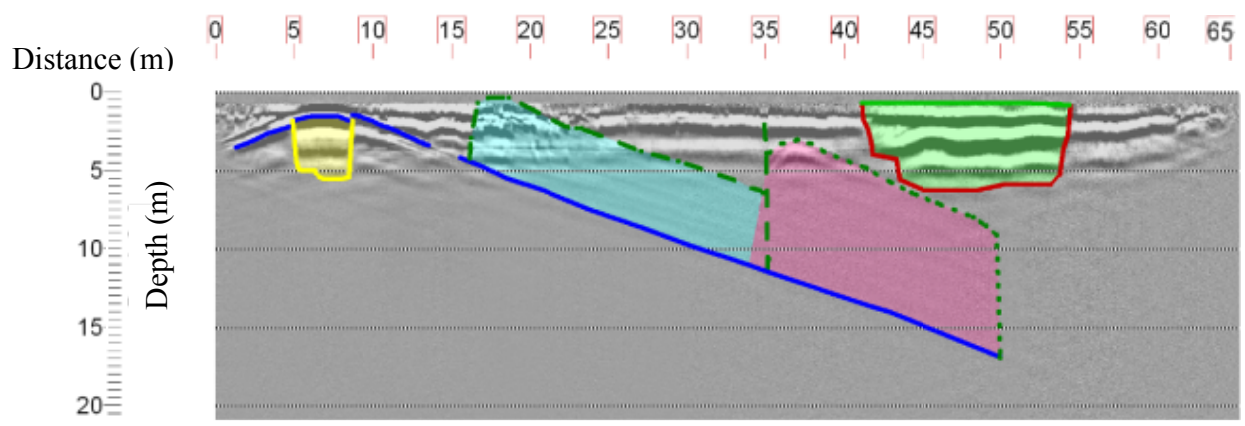

Fig. 7 GPR processed radargram.

Fig. 7 also shows some contrasts that might well be correlated to possible leachate pools within the waste mass. Those areas were delineated by the pink and green surfaces. In addition to that, the region enclosed by the yellow line might well contain an empty space within the landfill. Excavations carried out by contractors hired by the landfill owner confirmed that this was the case.

\section{Conclusions}

Gramacho's landfill owners were long searching for a tool that could indicate slip surfaces, leachate and greenhouse gases pools within the waste mass. GPR seemed to be a feasible technique since it is non-invasive and fast to perform and process its data. Slip surfaces could be indicated by small continuous voids within the waste mass since there is a good contrast between the dielectric constant of air and municipal waste. Greenhouse gases pools could also be indicated by large voids within the waste mass since there is a good contrast between the dielectric constant of carbon dioxide and methane and municipal waste. Finally, leachate pools present a high electric conductivity that could be easily be detected by GPR.

The results presented in this paper have shown that GPR is an useful tool not only to detect slip surfaces but also could indicate possible leachate pools within a landfill.

\section{References}

[1] Bertolla, L., Porsani, J. L., Soldovieri, F., and Catapano, I. 2014. "GPR-4D Monitoring a Controlled LNAPL Spill in a Masonry Tank at USP, Brazil." Journal of Applied Geophysics 103: 237-44.

[2] Castro, D. L., and Branco, R. M. G. C. 2003. "4-D Ground Penetrating Radar Monitoring of a Hydrocarbon Leakage Site in Fortaleza (Brazil) during Its Remediation Process: A Case History." Journal of Applied Geophysics 54: 127-44.

[3] Souza, M. M., Araruna Jr., J. T., and Antunes, F. S. 2006. "The Use of GPR in Environmental Site Investigation." In Proceedings of the XIII Brazilian Soil Mechanics and Geotechnical Engineering Conference, 1437-42. (in Portuguese)

[4] Souza, M. M., Araruna Jr., J. T., Antunes, F. S., and Ferreira, C. M. 2006. "The Use of GPR to Detect Water Leaks." In Proceedings of the XIV Brazilian Groundwater Conference, 1-15. (in Portuguese)

[5] Araruna Jr., J. T., Pires, P. J. M., Pilotto, D. L. P., and Amaral, C. P. 2007. "Considerations about the Use of GPR to Detect Buried Structures in Urban Environments." In Proceedings of the VII Brazilian Environmental Geotechnics Conference, 1-11. (in Portuguese)

[6] Porsani, J. L., and Sauck, W. A. 2007. "Ground-Penetrating Radar Profiles over Multiple Steel Tanks: Artifact Removal through Effective Data Processing." Geophysics 72: 77-83.

[7] Porsani, J. L., Slob, E., Lima, R. S., and Leite, D. N. 2010. "Comparing Detection and Location Performance of Perpendicular and Parallel Broadside GPR Antenna Orientations." Journal of Applied Geophysics 70: 1-8.

[8] Porsani, J. L., Ruy, Y. B., Ramos, F. P., and Yamamnouth, G. R. B. 2012. "GPR Applied to Mapping Utilities along the Route of the Line 4 (Yellow) Subway Tunnel Construction in São Paulo City Brazil.” Journal of Applied Geophysics 80: 25-31.

[9] Rodrigues, S. I., Porsani, J. L., Santos, V. R. N., De Blasis, P. A. D., and Giannini, P. C. F. 2009. "GPR and Inductive Electromagnetic Surveys Applied in Three Coastal Sambaqui (Shell Mounds) Archaeological Sites in Santa Catarina State, South Brazil.” Journal of Archaeological Science 36: 2081-8. 
[10] Iyomasa, W. S., Galli, V. L., Blanco, R. G., and Campos, G. C. 2006. "The Use of GPR to Detect Buried Pipelines in Urban Environments.” Soil and Rocks 29 (2): 177-88. (in Portuguese)

[11] Araruna Jr., J. T., Nunes, C. M., Costa, A., and Vargas Jr., E. A. 2002. "The Use of Ground Penetrating Radar to Detect Foundation Elements." In Proceedings of the XII Brazilian Soil Mechanics and Geotechnical Engineering Conference, 135-46. (in Portuguese)
[12] Porsani, J. L. 1999. Ground Penetrating Radar (GPR): Methodological Proposal for Geological and Geotechnical Studies." D.Sc. thesis, Instituto de Geociências e Ciências Exatas, UNESP (Universidade Estadual Paulista). (in Portuguese)

[13] Annan, A. P., and Cosway, S. W. 1992. "Ground Penetrating Radar Survey Design.” In Proceedings of the 1992 Symposium on the Application of Geophysics to Engineering and Environmental Problems, 329-52. 